\title{
A ESCRITA ALFABÉTICA E O XAMANISMO INDÍGENA
}

\author{
Celia Letícia Gouvêa Collet \\ Universidade Federal do Acre-Brasil
}

\section{RESUMO}

A finalidade do presente artigo é discutir a relação entre xamanismo e algumas formas de expressão gráfica (desenho, pictografia e escrita alfabética), com o intuito de melhor compreender o processo de absorção da escrita pelos grupos indígenas na Amazônia. Para isso, iremos analisar dados relativos a quatro grupos indígenas, os Piro/Manchineri, Kaxinawá, Yanomami e Bakairi.

PALAVRAS-CHAVE: Amazônia. Escrita Alfabética. Xamanismo. Pictografia. Grupos Indígenas.

\section{Desenho e Xamanismo}

Tendo como referência o texto de Peter Gow "Visual Compulsion: design and image in Western Amazonian Cultures" iremos discorrer sobre a relação do desenho com as idéias e práticas xamânicas dos Piro (povo indígena localizado no Rio Urubamba - Peru, sendo seus representantes no Acre - Brasil denominados Manchineri).

Em primeiro lugar, para compreendermos essa relação entre xamanismo e desenho, temos que entender a noção de corpo entre os povos indígenas da Amazônia, pois nela está a ponte entre esses dois domínios distintos. O corpo é o local privilegiado para se marcar a identidade, ou seja, é sobre ele que se imprimem as diferenças e as igualdades individuais e coletivas. O corpo é a matéria básica da comunicação e da significação, por isso é que há grande valorização por parte dos grupos indígenas do que se come, dos ornamentos e também das pinturas corporais (VIVEIROS DE CASTRO, 1986).

Entre os Piro, o parentesco é definido em termos de mistura de sangue e pela convivência e proximidade corporal (com importância especial para a alimentação). Não é, portanto, o fato de falar a mesma língua que faz alguém ser considerado Piro, mas a comunicação entre corpos (LAGROU, s/d; GOW,1988). A pintura seria o que há de mais expressivo nesse processo de fabricação do corpo. Para os Piro, o má- 
ximo de beleza e perfeição é representado pela figura da moça púbere quando sai do período de reclusão e tem seu corpo todo desenhado. A pintura é considerada tanto mais bonita quanto ela se adequar perfeitamente à forma do corpo, estabelecendo harmonia entre o desenho e a superfície corporal.

Verificamos aqui uma diferença básica entre a nossa concepção de desenho e escrita e a indígena. Para nós, o desenho é algo livre da superfície, independente do corpo sobre o qual é pintado, já entre os Piro, desenho e superfície corporal nunca são vistos separadamente, e a adequação à superfície é o principal desafio para uma boa desenhista. O desenho em si não diz nada, pois ele é principalmente uma forma de valorizar o corpo. Assim, Peter Gow nega que o desenho tenha algum significado por si só, que possa estar, por exemplo, representando a pele de uma onça ou de uma cobra.

Entre os Piro a sucuri e a onça além de serem motivos para pintura são também considerados xamãs, pois, ter desenho significa ter espírito. Na mitologia Kaxinawá a sucuri está tanto na origem do desenho quanto da ayahuasca, sendo chamada de "mãe da ayahuasca" (LAGROW, 1996).

Desse ângulo apreendemos o corpo como local da identidade e o desenho como forma de realçá-lo e, podemos arriscar a dizer que mais que ter a função de representar um animal ou outro ser, o desenho dota este corpo de um ponto de vista, de uma perspectiva. Da mesma forma que o uso de plumagens e máscaras usadas em diversos rituais, a pintura corporal também ativa a potência de um corpo-animal (VIVEIROS DE CASTRO, 1996; VILAÇA, 2000). Neste sentido, antes da pintura de motivos baseados na pele da sucuri ser uma representação da sucuri, ela é uma forma de adotar a perspectiva da sucuri.

A importância do desenho também está relacionada à sua capaci- 
dade transformadora. Ele está sempre presente em situações em que se quer enfatizar a transição, seja no caso citado anteriormente da moça que é pintada ao sair da reclusão para adquirir novo status social, seja quando se toma a ayahuasca e aparecem desenhos marcando o estágio de transição para o mundo das imagens, dos espíritos. Segundo Lagrou,

Na vida real, onde a eficácia está nos corpos e onde se lida com imagens substanciais, a função do desenho é a de enfatizar a superfície da forma corporal e a de marcar o fim do processo de fabricação dos novos corpos. Durante o ritual da ayahuasca, no entanto, a função do desenho seria, segundo Gow, o contrário. O desenho anunciaria a mutabilidade visual, a decomposição dos corpos e o aparecimento de formas não-substanciais: as imagens dos espíritos (LAGROU, s/d: 9).

Sobre a aparição de desenhos quando se toma a ayahuasca, os antropólogos vêm se questionando a respeito da relação que haveria entre os motivos dos desenhos e as imagens propiciadas pelo alucinógeno. A hipótese de uma relação de causalidade onde os desenhos corporais teriam sua origem nas visões da ayahuasca é rebatida por Gow através de três argumentos: o primeiro se baseia na falta de comprovação de que os desenhos originais seriam os imaginários e não os concretos; o segundo argumento é que as mulheres, parte do grupo responsável pela pintura, não tomam ayahuasca e por isso não poderiam se inspirar nesta fonte para a realização de seus trabalhos manuais; e o terceiro faz alusão ao fato dos desenhos, como já nos referimos anteriormente, nunca serem vistos separadamente dos corpos. Deve-se sempre levar em consideração o conjunto desenho/ superfície corporal, e o que aparece no início da viagem da ayahuasca é apenas imagem sem a superfície correspondente.

A atividade feminina de desenhar motivos animais sobre corpos humanos pode ser percebida, portanto, como parte do sistema xamâ- 
nico, como atividade necessária na construção dos corpos enquanto dotados de perspectiva:

O homem ritualmente vestido de animal é a contrapartida do animal sobrenaturalmente nu: o primeiro, transformado em animal, revela para si mesmo a distintividade "natural" do seu corpo; o segundo, despido de sua forma exterior e se revelando como humano, mostra a semelhança "sobrenatural" dos espíritos. O modelo do espírito é o espírito humano, mas o modelo do corpo é o corpo animal (VIVEIROS DE CASTRO, 1996: 131).

Neste sentido, Lagrou nos conta sobre a relação que existe entre mulher e desenho e homem e ayahuasca entre os Kaxinawá. Segundo ela, o universo do desenho e o universo do canto e ayahuasca não são diferentes, mas complementares, são os dois lados do poder xamânico.

O yuxin, que significa imagem e também pode ser simplificadamente, traduzido como "espírito", faz-se visível através do desenho ou da linguagem visual cantada, pois, no cotidiano, o mesmo somente pode ser visto sob a forma de animal ou planta. Os homens entram em contato com yuxin através da ayahuasca e se expressam pelo canto, enquanto as mulheres sonham e se expressam através dos desenhos.

Lagrou destaca ainda que não analisa os Kaxinawá através de dualismos, mulher e cultura de um lado e homem e sobrenatureza do outro. O que ela observa entre este grupo indígena é a importância da polaridade interno/externo, onde o primeiro termo significa o social e o segundo a floresta, os espíritos e os estrangeiros, ou seja, o outro. Neste sentido, a complementaridade entre o universo masculino e o feminino revela-se em termos de direção: os homens penetrando no mundo externo dos espíritos, e as mulheres no seu tecer e pintar cotidiano, criando estilos a partir da combinação entre a forma e os elementos incorporados de fora de seu grupo social, perfazendo, portanto, o percurso inverso do masculino, em um movimento de fora para dentro (LAGROU, 1996).

Mais uma vez percebemos o desenho particularmente manifes- 
tando-se em situações de transição. Nas sociedades que privilegiam o sentido da visão, como os Piro e Kaxinawá, o desenho tem uma relação importante com o xamanismo, pois "ver" é "conhecer". É através da visão que se entra em contato com o mundo desconhecido como o das causas das doenças ou o esconderijo da caça (LAGROU, s/d).

Observamos também a importância que os Kaxinawá atribuem ao corpo, tanto como objeto do olhar, quanto como sujeito, pois além de estar permanentemente sendo construído de diversas formas, inclusive através dos desenhos, passa por ele também a capacidade de perceber os outros corpos e imagens através do olho, ou melhor, do "espírito do olho" "responsável pela percepção visual e raciocínio sintético" (LAGROU, 1996).

\section{Incorporação da escrita alfabética}

Tendo visto acima a relação íntima entre grafismo e xamanismo, entre os Kaxinawá e os Piro, iremos agora perceber como a escrita alfabética, enquanto "grafismo do branco", é assimilada através do referencial xamânico indígena. Nos basearemos nos casos dos Piro/ Manchineri (Peru e Acre), Yanomami (Roraima) e dos Bakairi (Mato Grosso).

\section{Os Piro}

Na década de 40, o SIL $^{1}$ iniciou a implantação da escola entre os Piro. Até esta época eles estavam submetidos aos patrões em um regime praticamente escravo, visto que estavam presos aos brancos pelas dívidas contraídas. Em face dessa situação, eles relacionam o processo de alfabetização e o SIL com o período de liberdade, e o analfabetismo ao período de servidão.

1 "Summer Institute of linguistics", missão evangélica que atua entre os grupos indígenas da América Latina, através, principalmente da implantação de escolas bilingues, visando a alfabetização e tradução da Bíblia em língua indígena. 
A escrita, como todo fenômeno novo introduzido em uma cultura, foi absorvida a partir das referências preexistentes entre os Piro. O texto "Could Sangama Read?" (GOW, s/d) nos ajuda a compreender como aconteceu a relação inicial dos Piro com a escrita. O artigo se baseia no relato feito por Zumaeta, um índio Piro, a um missionário do SIL na década de 40, e conta a experiência de Sangama, um índio que "lia" jornais e livros de uma forma própria, relacionando-se com eles através do referencial que tinha antes da introdução da escrita: o xamanismo.

Zumaeta conta que, entre outras coisas, seu primo "lia": "Minha Manaus, meu Pará, minha Europa" (GOW, s/d: 5), o que remete exatamente ao itinerário da empresa seringalista, ao caminho da dívida como descrito por Manoela Carneiro da Cunha:

Aqui o sistema desposava a própria geografia: os negociantes ingleses adiantavam as mercadorias para os negociantes de Belém, que as repassavam para os de Manaus, que as forneciam aos "patrões" dos rios caucheiros, que abasteciam seus subpatrões, que por sua vez as transferiam aos seus próprios subpatrões, concluindo-se o conjunto com adiantamentos em mercadorias feitos aos seringueiros. Esta cadeia toda estava fundada sobre o aviamento, o crédito e a dívida; salvo nas extremidades (isto é, os peixes pequenos das cabeceiras e os grandes de Belém e de Liverpool), cada qual era credor a montante e devedor a jusante (CARNEIRO DA CUNHA, 1998: 10).

Essa geografia seria uma metáfora das relações de poder: os que estão à jusante do rio são os mais poderosos, pois têm uma visão mais global do sistema, da mesma forma que o poder dos xamãs vem do seu conhecimento de outros domínios, sendo, desta forma, além de geógrafos, tradutores entre dois mundos (CARNEIRO DA CUNHA, 1998).

Percebe-se, portanto, a identificação que Sangama faz entre a leitura de jornais e livros e o xamanismo, pois, tanto no primeiro caso 
quanto no segundo, temos uma relação entre dois mundos, uma tradução. Através do jornal os brancos entram em contato com o "outro mundo", o mesmo que faz o xamã através de suas práticas, cantos e uso de alucinógenos: “os xamãs são operadores da ligação entre o que está separado no espaço e no tempo (e no espaço porque no tempo)" (VIVEIROS DE CASTRO, 1986: 5).

Dessa forma, quando Sangama diz ao seu primo Zumaeta que "o papel quer conhecê-lo", e este duvida que o papel tenha intencionalidade, Sangama responde que "é costume do papel conversar", pois "o branco conversa com ele todo dia". Ele interpreta a leitura através do seu referencial xamânico, por isso ele se relaciona com o jornal de sujeito para sujeito, e não, como nós fazemos, de sujeito para objeto. Para ele, o jornal é dotado de uma perspectiva: "Olha, ela fala comigo, o papel tem um corpo, eu sempre a vejo, primo. (...) Ela tem lábios vermelhos com os quais fala. Ela tem um corpo com uma boca vermelha, uma boca pintada" (GOW, s/d.: 5).

No xamanismo "conhecer" é personificar, subjetivar e, portanto, para Sangama o papel é gente, tem corpo e boca, ele se comunica enquanto corpo, papel, e não enquanto letras, códigos sobre o papel.

Sobre este ponto, lembraremos do já descrito anteriormente sobre os desenhos dos Piro. Vimos que estes são concebidos apenas em conjunto com a superfície corporal desenhada, o desenho em si não significa nada, a sua importância está relacionada à valorização da superfície sobre a qual se imprime. Assim, Sangama não vê os símbolos gráficos da escrita como o que importa no jornal, mas enfatiza a superfície corporal (o papel).

Sangama percebe o ato de ler, menos como uma decifração de códigos que desde conhecidos permitem a leitura, e mais como a capacidade de ver o que os outros não vêem, capacidade típica do xamã. 
A informação lhe é passada através da boca do papel: devido à sua referência xamânica ele vê a imagem que se revela através do papel, como o que acontece quando se usa ayahuasca e então os espíritos se revelam enquanto pessoas em suas formas corporais. Da mesma forma que os desenhos introduzem as visões da ayahuasca, as letras do jornal introduzem a imagem que irá lhe informar sobre seus parentes que vivem longe (GOW, s/d).

\section{Yanomami}

É interessante observar como cada grupo constrói diferentemente sua relação com a escrita, de acordo com sua história e sua cosmologia. Enquanto os Piro identificam a escrita alfabética ao período em que o SIL esteve entre eles, lembrado como a época da liberação em relação ao jugo dos patrões, os Yanomami tiveram o contato com a escrita no momento em que lutavam para defender suas vidas das epidemias trazidas pelos brancos, e posteriormente as suas terras do impacto dos garimpos em sua área.

Bruce Albert analisa o discurso de Davi Kopenawa, líder deste movimento. Davi deixou sua região de origem

depois da morte de sua mãe (1967) numa epidemia de sarampo trazida para a área pelos filhos de um casal de missionários evangélicos da Novas Tribos do Brasil. Alfabetizado em sua língua para ler a Bíblia, Davi deixou então, com raiva no peito, "as palavras de Deus" (teosi $t \ddot{e} \tilde{a}$ ) por aquelas da fronteira regional, tornando-se, nos anos 1970, intérprete da FUNAI (ALBERT, 1995: 7).

Por essas diferenças históricas, ao invés de absorver a escrita positivamente como Sangama, o discurso de Davi quer marcar o antagonismo, colocando o conhecimento do branco através da escrita como inferior ao conhecimento verdadeiro dos xamãs:

Vocês brancos mentem. Não vêem-conhecem as coisas. Vocês acham que as conhecem, mas só vêem os desenhos de sua escrita". 
A escrita simboliza o universo do branco e é interpretada neste contexto de desqualificação do outro-ameaçador: "A escrita é, pois, um simulacro de "visão"que só remete ao domínio dos manufaturados e das máquinas do qual os Yanomami estão excluídos. É um saber desprovido de "ver" xamânico da "imagem essencial" (utupë), do "sopro" (wixia) e do "princípio de fertilidade" (në rope) que fazem a "beleza" da floresta (ALBERT, 1995:11).

O discurso de Davi, ao utilizar categorias políticas do branco e também as imagens cosmológicas Yanomami, reflete sua história individual e seu papel na situação de contato interétnico: ele é um tradutor entre dois mundos, entre duas linguagens, a xamânica e a política. Como um xamã, ele teve a capacidade de atualizar a mitologia para incorporar novos fenômenos, inclusive a escrita. Assim, nas palavras de Davi, Omamë, personagem mítico criador dos Yanomami disse:

Não destruam o lugar onde moram os meus genros [os Yanomami] e meus espíritos xamânicos! É assim que a "natureza" fala aos brancos, mas eles não entendem. São surdos e ignorantes. Seu pensamento é perturbado por vertigens. Olham para suas peles/cascas de imagem (utupë siki) e aí vêem outras coisas: o desenho da escrita das coisas que estão debaixo da terra e que eles desejam, o metal e o ouro. E assim se vangloriam de serem inteligentes (ALBERT, 1995: 20).

Podemos observar, portanto, que aparentemente Davi e Sangama partem de referenciais distintos, mas numa análise mais aprofundada vemos que ambos se utilizam da lógica xamânica. Como já dissemos, a visão xamânica valoriza o máximo de subjetividade, e assim Sangama vendo a escrita de forma positiva trata o jornal como sujeito, e Davi relacionando a escrita ao universo destruidor do branco, a rebaixa ao nível de objeto, destituindo-lhe de poder. Veremos ainda o caso Bakairi, a partir da observação de sua realidade escolar. 


\section{Bakairi $^{2}$}

Os Bakairi, indígenas de língua karib, localizados no Estado de Mato Grosso, passaram a ter contato com a língua portuguesa e com a escrita alfabética a partir de 1922, quando foram definitivamente confinados no Posto de Atração Simões Lopes do Serviço de Proteção aos Índios (SPI). A escola do Posto passou a funcionar desde o primeiro ano, sendo uma instituição fundamental dentro da filosofia civilizacionista rondoniana defendida pelo SPI. O aprendizado da língua portuguesa pelos Bakairi era um objetivo fundamental do órgão indigenista, que entre outros métodos utilizou-se de castigos físicos para punir os alunos que falassem a língua indígena na escola.

Entretanto, depois de tantas décadas de submissão a políticas civilizacionistas, os Bakairi mantém sua língua, e mais que isso, fizeram dela um lugar de resistência e valorização de sua identidade.

Atualmente, chama atenção no cotidiano escolar mecanismos que evitam a submissão da oralidade bakairi à escrita "branca", através da dissociação dos dois domínios na performance escolar. Assim, em uma aula, a escrita (no quadro, nos cadernos) é em português e a fala em língua bakairi. A escrita não representa a oralidade, elas existem separadas.

Na língua bakairi há duas palavras que se referem a grafismo/ desenho. "Iwenily" é o grafismo feito junto com uma superfície, indissociável dela, como, por exemplo, um desenho corporal ou um cesto desenhado. Este grafismo está relacionado ao processo de transformação xamânica, como acontece nos rituais quando corpos e máscaras "viram" os espíritos referentes aos grafismos com os quais são desenhados.

2 As informações sobre os Bakairi estão baseadas em minha pesquisa de campo desenvolvida entre 2000 e 2006 que resultou na tese de doutorado "Ritos de Civilização e Cultura: a escola bakairi". 
"Ekudyly" é o termo utilizado para o grafismo-representação, como, por exemplo, referindo-se a um mapa que representa um espaço ou um desenho que pretende imitar uma pessoa ou uma coisa.

O termo que os Bakairi escolheram para designar a escrita alfabética é "iwenyly", o que mostra o local designado a ela: o da transformação xamânica, sendo neste novo contexto, o "mundo dos brancos" o lugar espiritual/real a ser contatado. A escrita, portanto, seria uma forma dentro da performance escolar dos Bakairi de domesticação de um mundo externo poderoso (como o dos espíritos). Neste processo, eles estão no centro da ação, e não submetidos a um "outro".

A negação da tradução por "ekudyly" demonstra, por sua vez, o afastamento da idéia de escrita como representação da oralidade e, portanto, da submissão da oralidade bakairi à escrita ocidental.

A etnografia da performance escolar bakairi levou-me a entender a utilização do contexto da relação entre oralidade e escrita por eles como forma (profunda) de resistência ao processo colonial ainda em curso, sendo fundamental para a manutenção de sua identidade frente à sociedade brasileira e também de sua forma tradicional de se relacionar com o mundo, o xamanismo.

\section{Transformação, xamanismo e escrita}

Transformar-se a partir do uso ritual de roupas, máscaras ou pinturas, na visão dos Bakairi, diz respeito a assumir uma nova 'identidade', sem que isso represente nem um estado irreversível nem o abandono de outras 'identidades'. Na verdade o termo 'identidade' é apenas uma aproximação, sendo por mim utilizado por falta de outro conceito que consiga abarcar todo o sentido do processo de transformação a que estou me referindo.

Ainda, quanto a possibilidade de coexistência de mais de uma 
'identidade', diria que entre os Bakairi ocorre processo idêntico ao relatado por Aparecida Vilaça sobre os Wari', os quais, diz ela,

querem continuar a ser Wari' sendo Brancos. Em primeiro lugar porque desejam as duas coisas ao mesmo tempo, os dois pontos de vista e também querem preservar a diferença sem no entanto deixar de experimentá-la. Nesse sentido, vivem hoje uma experiência análoga à de seus xamãs: têm dois corpos simultâneos, que muitas vezes se confundem. São Wari' e Brancos, às vezes os dois ao mesmo tempo, como no surto dos xamãs (Vilaça, 2000: 69).

A título de ilustração desse fenômeno, a partir da realidade escolar bakairi, lembro de certa ocasião em que eu estava ajudando um professor na elaboração de um projeto a ser encaminhado à FUNAI para solicitar bolsas escolares. Ele me disse "neste momento sou um branco, pois estou fazendo coisa de branco". Com este comentário o professor quis dizer que se ao adotar um comportamento de 'branco' ('fazer projeto') ele estaria assumindo a 'identidade' de 'branco', de forma alguma isto implicaria no abandono de sua 'identidade de índio', muito menos numa transformação definitiva em 'branco'. Estava tão somente adotando um comportamento que o fazia 'virar branco', sem que isso acarretasse uma mudança irreversível ou a perda de sua 'identidade' bakairi.

Será a partir dessa idéia de transformação que iremos abordar daqui para frente as práticas cotidianas, o comportamento e a organização escolar, tratando-os como modalidades de iwenyly, isto é, como modos de familiarização (com) e transformação (em) 'civilizado', e especialmente no que se refere a sua escola,_onde os professores e alunos bakairi 'viram civilizados' a partir do momento em que realmente vivenciam esta 'identidade', como também acontece com aquelas pessoas que vestem as máscaras nos rituais em relação aos espíritos-animais que estas animam. No caso da escrita, a primeira a ser analisada, a relação com iwenyly é óbvia, sendo esta a sua tradução na língua 
bakairi. Depois dela, serão tratados outros aspectos que caracterizam o universo escolar: roupas, edifícios, disciplina e organização.

A escrita alfabética nasce, segundo Deleuze e Guattari (1976), quando grafismo e voz se unem, a partir de um primeiro movimento que subordina o primeiro a segunda e, depois, finalmente, de um segundo movimento que subordina a segunda ao primeiro. Neste momento, a escrita suplanta a oralidade em um movimento despótico ${ }^{3}$. O significante suplanta o significado e o que era baseado na inscrição passa a ser representação. "A voz não canta mais, mas dita, edita; a grafia não dança mais e deixa de animar os corpos, mas se escreve coagulada sobre tábuas, pedras e livros." (Deleuze e Guatari, 1976:260). Esta visão do "surgimento' ${ }^{4}$ da escrita pode nos ajudar a entender como atualmente os Bakairi lidam com ela.

A identificação pintura/escrita sob o termo iwenyly nos indica que a escrita pertence ao "plano de imanência", ${ }_{5}^{5}$ portanto, não servindo como representação, inclusive da "voz". Há entre os Bakairi meca3 Deleuze e Guatarri (1976) recuperaram ironicamente a clássica seqüência evolucionista - selvagens, bárbaros e civilizados - como uma forma de tratar a dinâmica social de transformação. Eles, entretanto, descartam qualquer visão tipológica e evolutiva, ou seja, cada um dos termos não corresponde a um momento da evolução social e nem mesmo cada sociedade tem necessariamente que estar classificada em um deles. Eles são concebidos como regimes de codificação dos fluxos que podem aparecer e se combinar em qualquer formação social, o primeiro agindo através de codificação e inscrição, o segundo através da sobre-codificação e o terceiro da axiomatização desses fluxos. A origem da escrita estaria relacionada ao regime bárbaro ou despótico da sobre-codificação, juntamente com o Estado, o "Édipo" e a Lei, quando o significante salta do plano de imanência e ganha preponderância sobre o significado.

4 Falo de "surgimento", pois mesmo sabendo que a escrita veio a principio "de fora" como uma imposição, vejo que ela foi apropriada a partir de um modo próprio bakairi, podendo, portanto, neste sentido, ser tratada também como resultado de um movimento interno.

5 Termo de Deleuze e Guatari (1976) que se refere a uma situação da relação entre voz e grafismo em que ainda o significante não sobrepujou o significado, ou seja, não há representação, nem a possibilidade da pergunta "o que isso quer dizer?". 
nismos de separação entre voz e escrita que podem ser aproximados daqueles descritos por Elsje Lagrou (1996) para os Kaxinawá e por Carlo Severi (1985) para os Cuna.

Entre os Cuna, segundo Carlo Severi, a separação entre voz e grafia revela a seguinte lógica: o xamã utiliza as pictografias como técnica auxiliar de memorização para transmitir conhecimentos aos seus seguidores. O aprendizado é dividido em dois momentos, o primeiro se refere à memorização dos cantos e o seguinte, a título de complementação e afirmação do primeiro, é caracterizado pelo ensino das pictogravuras, que ajudam a compreender as alusões e indicações obscuras existentes no canto, onde boa parte do sentido se dá apenas de forma implícita. O grafismo é, aqui, utilizado para organizar a sucessão temporal e espacial dos eventos e ajuda a fixá-los na memória do aprendiz, além de mostrar algumas estruturas cosmológicas que o canto não revela e não descreve.

Kaxinawá e Cuna seriam dois exemplos da situação em que voz e grafia podem ser consideradas complementares, mas separadas. Os Kaxinawá, ao identificarem voz e grafismo a homens e mulheres distintamente, estariam, portanto, mantendo longe a possibilidade de que esses domínios venham a se juntar (e de que posteriormente haja a submissão de um ao outro). Os xamãs cuna, por sua vez, apesar da relação forte entre grafia e canto, não estabelecem entre os dois planos uma relação de subordinação ou representação. A pictografia não representa o canto, ela o complementa.

Entre os Bakairi, a partir do universo escolar, podemos apontar alguns mecanismos que da mesma forma mantêm a separação da escrita e da voz: a escrita é tratada apenas em sua relação com a superfície (iwenyly); a leitura é sempre oral (em voz alta); a escrita livre (em oposição à cópia) segue estruturas e reproduz marcas da oralidade; o 
texto construído fielmente sobre as bases da línguagem escrita é entendido com muita dificuldade; há uma identificação constante entre, por um lado, língua portuguesa e escrita, e língua bakairi e oralidade, por outro. Vejamos agora o que é a escrita escolar, adentrando os momentos e os espaços das aulas onde o que acontece repousa basicamente no uso da escrita.

Em geral, nas aulas se sucedem os seguintes movimentos: o professor copia a matéria do livro para o quadro negro, para, então, se proceder a uma nova cópia ou transposição do texto escrito, feita, agora, pelos alunos, do quadro negro para os seus cadernos. A outra maneira de proceder durante uma aula é o professor e os alunos lerem em voz alta, em conjunto (uma leitura coral), um trecho ou um texto do livro. ${ }^{6}$ Tal procedimento poderia se explicar por ser ele o único recurso didático que chega aos professores ${ }^{7}$, mas me parece mais interessante pensar o livro como um 'material' (objeto ritual) fundamental na composição da performance escolar, correspondendo ao que seriam as máscaras rituais.

Vejamos, então, no contexto da aula qual é o tratamento dado à escrita: primeiro como 'cópia', depois como base para a leitura, sem ser nunca caracterizada pela subordinação da voz ao grafismo. No primeiro caso, só há grafismo, no segundo, o grafismo está subordinado à voz. Ainda, em todas as situações escolares podemos testemunhar que a escrita é sempre em português e a expressão oral preponderantemente em língua bakairi.

\section{Escrever/copiar na escola bakairi}

A partir do que vimos na seção anterior, escrever e 'transferir

6 Alguns_professores se arriscam a transmitir conhecimentos aprendidos durante o Projeto Tucum e o $3^{\circ}$ Grau Indígena, mas, via de regra, o livro didático é o seu guia.

7 Os livros didáticos do MEC chegam todos os anos para os alunos de $1^{\mathrm{a}}$ a $8^{\mathrm{a}}$ series. 
desenhos de uma superfície para a outra' são processos designados pelo mesmo termo: iwenyly. Dessa forma, para pais e alunos bakairi, escrever e saber copiar do quadro-negro são exatamente a mesma coisa. Quando um pai percebe que seu filho já sabe copiar corretamente o desenho-escrita ele diz que ele "já está escrevendo". Por outro lado, assim como copiar é escrever, também a afirmativa 'escrever é copiar' é verdadeira para o universo escolar bakairi, onde praticamente toda escrita é cópia. É difícil haver uma atividade em que o professor peça para os alunos escreverem 'livremente' (o que acontece somente nas redações, um gênero de escrita que passou a ser desenvolvido após a participação dos professores no Projeto Tucum e no $3^{\circ} \mathrm{Grau}$ Indígena). $\mathrm{Na}$ maior parte das vezes, os exercícios escolares são ou copiados do quadro negro ou, para os que constam nos livros didáticos, as respostas devem seguir exatamente o texto do livro; o mesmo acontece nas avaliações. Acompanhei alguns alunos estudando para provas, atividade feita sempre no dia anterior, e observei que o método desse estudo é muito mais o de 'decorar', com todas as palavras e pontuação, que o de procurar entender o conteúdo. Este, porém, é apenas o fim do processo de aprendizagem que, como vimos, inicia-se e desenvolve-se através da cópia. A este respeito, um professor do ensino médio me disse que seus alunos respondiam com muita facilidade a questões especificas e com respostas claras, mas que tinham grande dificuldade em discorrer sobre temas amplos, sem respostas exatas, ou em responder a perguntas feitas com pequenas alterações em relação ao modelo.

Nas aulas, além da prática da cópia da escrita, pode acontecer que um aluno tenha que compor um texto escrito ou que tenha mesmo que ler um texto sozinho. Isso raramente ocorre no Ensino Fundamental e Médio bakairi, mas podemos colher, no âmbito dos cursos de formação de professores, exemplos que ilustram a relação dos Bakairi com o texto escrito. Durante o Projeto Tucum de formação de profes- 
sores indígenas realizado pela Secretaria de Educação do Estado de Mato Grosso, diariamente, um dos alunos (professor indígena) lia a "memória do dia", um relato das atividades do dia anterior. A despeito dessa atividade ter sido idealizada como uma oportunidade deles exercitarem a escrita, a leitura da "memória do dia" era feita a partir de uma apropriação que privilegiava as referências orais, ou seja, utilizando-se de vários recursos relativos à expressão oral - gestos, diálogos - fazendo com que a escrita fosse mais uma transposição da fala. Um outro episódio foi significativo. Ao visitar a aldeia Santana, os professores bakairi, estudantes da UNEMAT, me pediram ajuda para realizar um "trabalho" de interpretação de texto. Percebi que apesar de conhecerem praticamente todo o vocabulário, não entendiam a estrutura do texto, pois esta seguia estritamente o modelo do discurso escrito. A ajuda possível foi, portanto, proceder a uma 'tradução' da linguagem escrita para a linguagem oral. Em ambos os casos, observamos que, para os Bakairi, o grafismo/escrita deve ser empregado não o separando da oralidade, mas o subordinando a ela.

Outro contexto de leitura que demonstra esse divórcio entre oralidade e escrita diz respeito ao livro didático, havendo, nesse caso, a possibilidade de ter-se tanto escrita sem leitura (apenas o desenho das letras no livro), quanto leitura sem escrita (no caso de decorar o texto e reproduzi-lo oralmente). Nas turmas que ganham livros didáticos $\left(1^{\mathrm{a}} \mathrm{a}\right.$ $8^{\mathrm{a}}$ series), os alunos se acostumaram a abri-los na página indicada pelo professor e acompanhar a leitura feita pelo mesmo. Pude notar, então, que todas as vezes que os professores me pediam para eu os substituir e eu tentava ministrar uma aula com atividades que não passassem pelo livro didático, usando principalmente explicações e diálogos, os alunos não conseguiam ficar sem o livro ou o quadro-negro como ponto de apoio. A explicação-oralidade, nesse caso, estava muito distante do que concebiam como uma aula, uma atividade, como vimos, basea- 
da essencialmente na cópia-escrita (iwenyly) ou na voz da leitura feita em tom alto e coletivamente.

Em suma, nas atividades realizadas durante as aulas - escrita ou leitura - verificamos o afastamento entre grafismo e voz a partir de vários mecanismos, que têm como efeito a manutenção do modelo -iwenyly característico da escrita, o que significa operar a relação com o 'mundo civilizado' através da 'transformação', negando a relação de representação, característica do modelo-ekudyly.

Toda forma de iwenyly, inclusive a escrita, seria vista pelos Bakairi como um meio para a tomada da perspectiva de um 'outro', ou seja, a apropriação de uma técnica de transformação. Em outras palavras, do mesmo modo que os iwenyly, enquanto pinturas dos corpos e objetos rituais são maneiras de se familiarizar com os iamyra aquáticos, isto é, as "roupas" que permitem sua transformação, também a domesticação dos "brancos" (civilizar-se) passa pelo domínio da escrita. 8 No entanto, vejamos que o que estou procurando entender da natureza da escrita se aproxima muito da forma como Aristóteles Barcelos Neto definiu as "roupas" dos yerupoho/apapaatai wauja (correspondentes aos iamyra dos Bakairi). Os "espíritos" wauja "vestem" "roupas" de animais e assumem sua perspectiva, fato que acontece não por imitação, mas por incorporação de suas capacidades. Segundo Barcelos Neto "A "roupa" é um dispositivo de atributos instrumentais e anatômicos - asas, no caso dos seres alados, garras e/ou presas, no caso dos predadores, entre outros. - que enseja capacidades físico-locomotoras especificas: voar, nadar, saltar, correr velozmente etc. Os humanos são os sem-"roupa" por excelência, com exceção dos feiticeiros, que podem fazer uso de "roupas" especiais" (Barcelos, 2004: 61).

8 Sobre este tema ver Peter Gow para o estabelecimento de ume a relação entre o uso de roupas dos "brancos" pelos Piro e o aprendizado de seus "desenhos" (escrita), como uma "transformação" do "desenho" (Gow, 2001: 127). 
Assim, da mesma maneira que as "roupas" dos animais bem como as pinturas corporais (iwenyly) dotam espíritos e pajés de capacidades relativas a esses seres (como também acreditam os Bakairi), o uso de 'roupas dos brancos' e da iwenyly-escrita teria o poder de ativar uma 'identidade civilizada' nos alunos e professores bakairi, ou, em outras palavras, permite que domestiquem a civilização.

\section{Xamanismo, grafismo e a introdução da escrita entre os indígenas}

Após a apreciação de todos esses casos que ilustram várias formas de relação entre xamanismo e expressão gráfica em grupos indígenas com histórias e cosmologias distintas, podemos observar a relevância que o desenho, a pictografia e a escrita podem ter nas práticas, ideologias e manifestações xamânicas. Essa análise, também, nos permite entender melhor como o xamanismo, através de sua característica fundamental de incorporar novos fenômenos, apresenta os parâmetros segundo os quais a escrita será absorvida por estas sociedades.

Antes mesmo da introdução da escrita alfabética entre os grupos indígenas através da escola, o grafismo já fazia parte de suas formas de expressão e comunicação. Assim, não podemos, pois, colocar de lado a cosmologia, o conhecimento xamânico e os rituais, se quisermos saber em quais bases a escola indígena se desenvolverá.

O maior conhecimento da organização social, da cultura, das ambições e das transformações efetuadas por essa experiência junto aos professores indígenas, vai possibilitando que, não só possamos apontar algumas idéias em relação ao futuro, como também, até mesmo modificar, dentro do possível, algumas previsões, através da atuação dos professores índios no sentido de fortalecer a identidade étnica do seu grupo e a sua atuação no âmbito social amazônico e brasileiro. 
Muiraquitã, PPGLI-UFAC, v.2, n.1, Jul/Dez, 2013

ALPHABETIC WRITING AND INDIGENOUS SHAMANISM

\section{ABSTRACT}

The purpose of this article is to discuss the relationship between shamanism and some forms of graphic expression (drawing, pictographs and alphabetic writing) in order to better understand the process of writing absorption made by indigenous groups in the Amazon. In order to do so we analyzed data relating to four indigenous groups: the Piro/ Manchineri, Kaxinawá, Yanomami and Bakairi.

KEYWORDS: Amazon. Alphabetic writing. Shamanism. Pictography. Indigenous groups.

\section{REFERÊNCIAS}

ALBERT, B. O Ouro Canibal e a Queda do Céu: Uma crítica Xamânica da Economia Política da Natureza. Brasília: UnB, 1995.

BRUNELLI, G. Do Xamanismo aos Xamãs: Estratégias Tupi-Mondé Frente à Sociedade Envolvente. In: Langdon, J. Xamanismo no Brasil: Novas Perspectivas. Florianópolis: UFSC, 1996.

CAPACLA, M. V. O Debate sobre Educação Indígena no Brasil (19751995): resenha de teses e livros. Cadernos de Educação Indígena, vol. I., Brasília/São Paulo: MEC/ MARI, 1995.

CARNEIRO DA CUNHA, M. Pontos de Vista sobre a Floresta Amazônica: Xamanismo e Tradução. Mana 4 (1): 7-22. Rio de Janeiro: Contracapa, 1998.

GOODY, J. Literacy in Traditional Societies. Cambridge: Cambridge University Press, 1975.

GOW, P. Visual compulsion: Design and Image in Western Amazonian Cultures. Antropologia em Primeira Mão. Florianópolis: UFSC, 1988.

GOW, P. River People: Shamanism and History in Western Amazonia. In: THOMAS, N. \& HUMPHREY, C. (ed), Shamanism, History and the State. Ann Arbor: Michigan University Press, 1994.

GOW, P. Could Sangama Read? Graphic Systems, Language and Shamanism among the Piro (Eastern Peru), S/d.

LAGROU, E. Xamanismo e Representação entre os Kaxinawá. In: LANG- 
DON, J. Xamanismo no Brasil: Novas Perspectivas. Florianópolis: UFSC. 1996.

LAGROU, E. Compulsão Visual: Desenhos e Imagens nas Culturas da Amazônia Ocidental. Antropologia em Primeira Mão. Florianópolis: UFSC. S/d.

MELIÀ, B. Desafios e tendências na alfabetização em língua indígena. s/d.

MONTE, N. Alfabetização e Pós-alfabetização indígena. Cadernos do CEDI n. 13, 1984.

MONTE, N. Escolas da Floresta. Rio de Janeiro: Multiletra, 1996.

OVERING, J. The Shaman as a Maker of Worlds: Nelson Goodman in the Amazon. Man 25 (4): 602-619. 1990.

SEVERI, C. Penser par Séquences, Pencer par Territoires: Cosmologie et art de la mémoire dans la pictographie des Indiens Cuna. S/d.

TOWNSLEY, G. Song Paths: The Ways and Means of Yaminahua Shamanic Knowledge. L'Homme 126-128, XXXIII (2-4). 1993.

VILAÇA, A. O que significa Tornar-se Outro? Xamanismo e Contato Interétnico na Amazônia. In: Revista Brasileira de Ciências Sociais v. 15, n. 44, 2000.

VIVEIROS DE CASTRO, E. Escatologia Pessoal e poder entre os Araweté. In: Religião e Sociedade 13 (3): 2-26. 1986.

VIVEIROS DE CASTRO, E. Pronomes Cosmológicos e Perspectivismo Ameríndio. In: Mana: Estudos de Antropologia Social 2 (2): 115-144. Rio de Janeiro: Contracapa, 1996. 